\title{
BMJ Open Factors associated with advanced stage at diagnosis of cervical cancer in Addis Ababa, Ethiopia: a population- based study
}

\author{
Nebiyu Dereje (D) , ${ }^{1,2}$ Alem Gebremariam (D) , ${ }^{1,3}$ Adamu Addissie, ${ }^{1}$ \\ Alemayehu Worku, ${ }^{1}$ Mathewos Assefa, ${ }^{4}$ Aynalem Abraha, ${ }^{4}$ \\ Wondemagegnehu Tigeneh, ${ }^{4}$ Eva Johanna Kantelhardt (D) , ${ }^{5}$ Ahmedin Jemal ${ }^{6}$
}

To cite: Dereje N,

Gebremariam A, Addissie A, et al. Factors associated with advanced stage at diagnosis of cervical cancer in Addis Ababa, Ethiopia: a populationbased study. BMJ Open 2020;10:e040645. doi:10.1136/ bmjopen-2020-040645

- Prepublication history and additional material for this paper are available online. To view these files, please visit the journal online (http://dx.doi. org/10.1136/bmjopen-2020040645).

Received 18 May 2020

Revised 18 August 2020

Accepted 17 September 2020

Check for updates

(C) Author(s) (or their employer(s)) 2020. Re-use permitted under CC BY-NC. No commercial re-use. See rights and permissions. Published by BMJ.

For numbered affiliations see end of article.

Correspondence to

Nebiyu Dereje;

neba.jahovy@gmail.com

\section{ABSTRACT}

Objective To describe the patterns and factors associated with advanced stage at diagnosis of cervical cancer among Addis Ababa residents, Ethiopia.

Design A population-based cross-sectional study. Setting Seven major hospitals or diagnostic facilities in Addis Ababa, Ethiopia.

Participants All histopathology-confirmed patients with incident cervical cancer diagnosed from 1 January 2017 to 30 June 2018 among Addis Ababa residents.

Outcome measures The proportion of patients with cervical cancer diagnosed at early stage (stage I/II) and advanced stage (stage III/IV) of the disease according to International Federation of Gynaecology and Obstetrics staging criteria, and adjusted prevalence ratio (APR) for factors associated with advanced-stage diagnosis using a Poisson regression with robust variance model.

Results The mean age of the study participants was 52.9 ( \pm 13.3$)$ years. Nearly two-thirds $(60.4 \%, 95 \% \mathrm{Cl}: 53.8 \%$ to $66.5 \%$ ) of patients with cervical cancer were diagnosed at an advanced stage. Advanced stage at diagnosis was significantly associated with paying medical bill out of pocket (APR=1.44, 95\% Cl: 1.08 to 1.91), diagnostic interval $>90$ days (APR $=1.31,95 \% \mathrm{Cl}: 1.04$ to 1.71 ), practicing religion as a remedy or not taking immediate action following symptom recognition (APR $=1.25,95 \% \mathrm{Cl}$ : 1.08 to 1.91) and visiting more than three different health facilities prior to diagnostic confirmation (APR $=1.24,95 \%$ Cl: 1.07 to 1.51).

Conclusions Our findings of the high proportion of advanced-stage diagnosis of cervical cancer in Addis Ababa and its strong associations with out-of-pocket medical bill, seeking care out of conventional medicine settings and multiple visits to healthcare facilities before diagnostic confirmations underscore the need for public policies to improve the affordability of cancer care and enhance community awareness about the severity of the disease and referral system, in addition to expanding cervical cancer screening.

\section{INTRODUCTION}

Cervical cancer is the second leading cause of cancer death in women in Ethiopia and other parts of Africa. ${ }^{12}$ Although cervical cancer
Strengths and limitations of this study

- This is the first population-based study to describe factors associated with advanced-stage cervical cancer diagnosis in African setting.

- All cervical incident cases in Addis Ababa may not have been included in the study because some patients might never have visited healthcare facilities or have visited local healthcare facilities that do not report incident cancers to the central cancer registry.

- Recall bias about dates of symptom recognition and of presentations might have also affected our findings.

can be prevented by detection and removal of precancerous lesions and treated successfully if detected early, ${ }^{3}$ most patients in Ethiopia ${ }^{45}$ and many other parts of Africa are diagnosed at advanced stage of the disease,${ }^{6-9}$ when the choice of treatment is limited and the probability of survival is less. Previous findings on stage distribution in Ethiopia and in most parts of Africa, however, may not be generalisable as they were hospital-based studies rather than population-based studies.

Several previous studies from sub-Saharan African countries associated advanced-stage cervical cancer diagnosis with low-level community awareness of the disease ${ }^{10}$ and with lack of screening services and diagnostic facilities. ${ }^{811}$ No previous study in the region, however, examined the associations between advanced-stage diagnosis and source of medical bill coverage, and other healthrelated patient behaviours and health system factors such as delay in seeking medical consultation after recognition of symptoms and delay in receipt of diagnostic confirmation after healthcare provider consultation. Therefore, this study was conducted to describe the stage distribution of cervical 
cancer among Addis Ababa residents and to identify factors associated with advanced stage of the disease based on all incident cancer cases diagnosed from 1 January 2017 through 30 June 2018 among the residents of the city.

\section{METHODS}

A multicentre cross-sectional study was conducted among all newly diagnosed patients with cervical cancer in Addis Ababa during the 18-month study period from 1 January 2017 to 30 June 2018. Patients were considered to be residents of the city if they lived there at least 6 months before the date of diagnosis. Study participants were recruited from seven major hospitals or diagnostic facilities aided by the Addis Ababa Population-based Cancer Registry, which actively registers all incident cancer cases among the residents of the city. ${ }^{12}$ During the study period, 234 histopathologically confirmed newly diagnosed patients were recorded in the registry. Of these patients, 22 were excluded from the study because they sought treatment abroad (3 patients) or because of lack of stage information in their medical records (19 patients).

All the cervical cancer cases were confirmed by histopathology and staged according to the 2014 International Federation of Gynaecology and Obstetrics (FIGO) criteria by senior gynaecological oncologist or clinical oncologist. ${ }^{13}$ In addition to physical examination, distant metastasis (stage $\mathrm{IVb}$ ) was determined by reviewing chest X-ray and abdominal ultrasound findings. ${ }^{14}$

A face-to-face interview was administered by trained nurse interviewers at around the time of diagnosis to collect data on sociodemographic and health behaviours using a structured questionnaire, adapted from previous surveys. ${ }^{911}$ Initially, the questionnaire was prepared in English and later translated to Amharic, the national language. The consistency of questionnaire translation was checked by back translation by an independent translator, and its contents were validated by experts (gynaecologists and oncologists).

Patients' clinical characteristics were extracted from medical charts by junior oncologists (residents) using a structured checklist, and any inconsistencies were resolved by consulting senior oncologists. Information on histology type and date of diagnostic confirmation was obtained from pathology reports.

Total diagnostic time interval was defined as the interval from the date of first symptom(s) recognition by the patient to the date of histological confirmation of the diagnosis. Total diagnostic interval was considered delayed if the interval was $>90$ days. ${ }^{15-17}$

The main outcome variable of the study was stage at diagnosis, which was grouped into two: early (stage I/ II) and advanced (stage III/IV). The independent variables include sociodemographic characteristics (age, educational status, marital status, family income, source of medical expense coverage), clinical characteristics (histological type, comorbidity) and other patient- or provider-related factors (diagnostic delays and number of health facilities visited prior to diagnostic confirmation).

Descriptive analyses were used to calculate summary statistics of frequencies, proportion, median, mean and SD. Bivariate and multivariable analyses using a Poisson regression with robust variance method were used to identify factors associated with patients being at an advanced stage of cervical cancer at diagnosis. The Poisson regression with robust variance method was used to directly estimate the prevalence ratio (PR) (the effect measure), since the OR (logistic regression) overestimates the effect when the prevalence (magnitude) of the outcome variable is not rare $(>10 \%) .{ }^{18}$ Those variables with $\mathrm{p}$ value $<0.25$ in bivariate analysis were considered for the multivariable analysis in the Poisson regression model. Level of significance was set at $p$ value $<0.05$ at $95 \%$ CI, and PR was used to quantify the strength of association for each variable. Postestimation fitness of this model was checked by $\chi^{2}$-based goodness-of-fit test, and the final model was found to be fit. There was no multicollinearity between the variables using collinearity diagnostics (variance inflation factors and tolerance). In accordance with the journal's guidelines, we will provide our data for the reproducibility of this study in other centres, if such is requested.

\section{Patient and public involvement}

Neither patients nor the public were involved in the design of this study.

\section{RESULTS}

\section{Sociodemographic and clinical characteristics}

The mean age of the study participants $(\mathrm{n}=212)$ was 52.9 $( \pm 13.3)$ years, with the majority $(68.4)$ being $<60$ years of age $(68.4 \%)$, Christians $(91.5 \%)$ and housewives $(63.2 \%)$. More than two-thirds $(67.5 \%)$ of the patients had a family monthly income below 3200 ETB (US\$100). Only $2.8 \%$ of the patients had a family history of cervical cancer. The majority of the patients $(98.6 \%)$ were non-smokers; however, about a quarter $(23.6 \%)$ of them were alcohol users. More than two-thirds $(68.4 \%)$ of the patients have paid their medical expenses out of pocket (table 1). The extent of delays to diagnosis of cervical cancer (patient and diagnostic) is described in a previous publication. ${ }^{19}$

More than two-thirds (69.8\%) of the patients had tumour size $>4 \mathrm{~cm}$. The majority of cervical cancer cases $(91.0 \%)$ were a squamous cell carcinoma. About one in five $(21.7 \%)$ patients with cervical cancer were HIVpositive, and all were on antiretroviral therapy.

\section{Stage at diagnosis of cervical cancer}

Nearly two of three (60.4\%, $95 \%$ CI: $53.8 \%$ to $66.5 \%)$ patients with cervical cancer were diagnosed at advanced stage, with $37.3 \%$ of them diagnosed at stage IV (figure 1). Furthermore, for about $5.2 \%$ of the patients, the disease had metastasised to lung $(2.4 \%)$, liver $(2.4 \%)$ or peritoneum $(0.5 \%)$ at diagnosis. 


\begin{tabular}{|c|c|}
\hline Variables & Frequency (\%) \\
\hline \multicolumn{2}{|l|}{ Age } \\
\hline$<40$ years & $42(19.8)$ \\
\hline 40-59years & $103(48.6)$ \\
\hline$\geq 60$ years & $67(31.6)$ \\
\hline \multicolumn{2}{|l|}{ Formal education } \\
\hline No & $86(40.6)$ \\
\hline Yes & $126(59.4)$ \\
\hline \multicolumn{2}{|l|}{ Family monthly income } \\
\hline$\leq 3200$ ETB & $143(67.5)$ \\
\hline$>3200$ ETB & $69(32.5)$ \\
\hline \multicolumn{2}{|l|}{ Source of medical expenses } \\
\hline Out of pocket & $145(68.4)$ \\
\hline Free/insured & $67(31.6)$ \\
\hline \multicolumn{2}{|c|}{ Immediate action after symptom recognition } \\
\hline Went to health facility & 149 (70.3) \\
\hline No action/Religious activity & $63(29.7)$ \\
\hline \multicolumn{2}{|c|}{$\begin{array}{l}\text { Number of different health facilities visited before diagnost } \\
\text { confirmation }\end{array}$} \\
\hline$\leq 3$ health facilities & $142(67.0)$ \\
\hline$>3$ health facilities & $70(33.0)$ \\
\hline \multicolumn{2}{|l|}{ Diagnostic interval } \\
\hline$\leq 90$ days & $68(32.1)$ \\
\hline$>90$ days & $144(67.9)$ \\
\hline \multicolumn{2}{|l|}{ HIV infection } \\
\hline Yes & $46(21.7)$ \\
\hline No & 166 (78.3) \\
\hline \multicolumn{2}{|l|}{ Tumour size } \\
\hline$\leq 4 \mathrm{~cm}$ & 64 (30.2) \\
\hline$>4 \mathrm{~cm}$ & 148 (69.8) \\
\hline
\end{tabular}

\section{Factors associated with advanced stage at diagnosis of cervical cancer}

In a bivariate analysis (online supplemental material), advanced stage at diagnosis (stage III/IV) was significantly associated with source of medical expenses, not going to healthcare facilities immediately after symptom recognition, visiting more than three different healthcare facilities before diagnostic confirmation and total diagnostic interval $>90$ days.

In the multivariable analysis (table 2), the proportion of advanced stage at diagnosis of cervical cancer was 1.4 times higher (adjusted prevalence ratio $(\mathrm{APR})=1.44,95 \%$ CI: 1.08 to 1.91 ) among women who paid their medical expenses out of pocket compared with women who were entitled to free medical service or having health insurance coverage. The proportion was 1.3 times higher (APR $=1.31,95 \%$ CI: 1.04 to 1.71 ) among women with a total diagnostic interval of $>90$ days than those with an

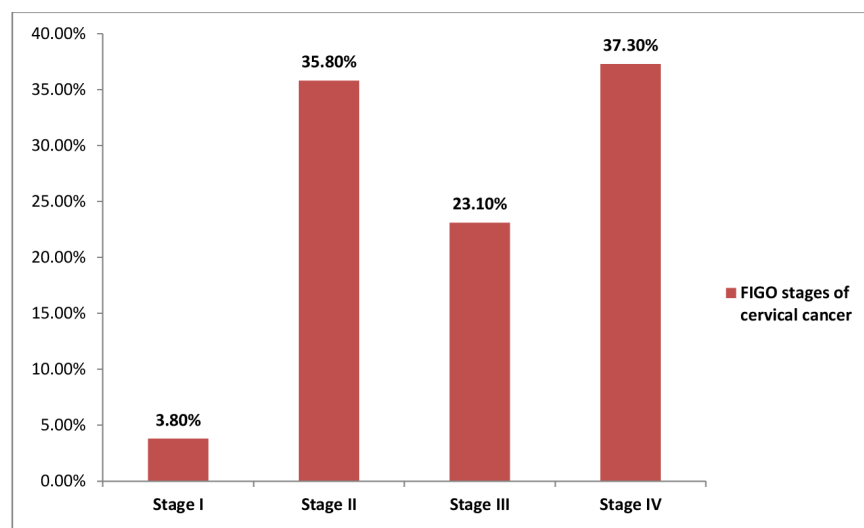

Figure 1 FIGO stages of cervical cancer at diagnosis of patients residing in Addis Ababa, 2018. FIGO, International Federation of Gynaecology and Obstetrics.

interval of $\leq 90$ days. Similarly, the proportion of being diagnosed at an advanced stage of cervical cancer was 1.25 times higher (APR=1.25, 95\% CI: 1.05 to 1.53 ) among women who went to religious practices or did nothing immediately after their symptom recognition compared with women who immediately went to healthcare facilities, and 1.2 times higher (APR=1.24, 95\% CI: 1.08 to 1.91) among women who visited $>3$ different healthcare facilities prior to diagnostic confirmation compared with those who visited $\leq 3$ healthcare facilities.

\section{DISCUSSION}

This study provides data on cervical cancer stage distribution in Addis Ababa along with its predictors based on a population-based study. We found that nearly two-thirds of patients with cervical cancer in Addis Ababa were diagnosed at an advanced stage of the disease, and that advanced stage at diagnosis was strongly associated with out-of-pocket medical bill coverage and with delays in diagnosis confirmation.

Although our finding of high proportion of advancedstage cervical cancer in Addis Ababa is generally similar to findings from other sub-Saharan African countries, ${ }^{811}$ it is slightly higher than that reported from Kenya $(53.9 \%)^{9}$ and lower than that reported from Sudan $(71.5 \%) .{ }^{20}$ The higher proportion in Sudan in part reflects the predominantly rural resident study participants, where access to healthcare facilities is limited and health literacy is expected to be lower. In contrast, the lower proportion in the Kenyan study may reflect the higher coverage of a recent cervical cancer screening programme in the country $(14 \%)^{21}$ compared with Ethiopia $(0.6 \%) .{ }^{22}$ In addition, the screening programme created awareness on cervical cancer. $^{21}$

Our findings also showed that the proportion of advanced-stage cervical cancer was considerably higher among women who waited for more than 3 months to receive diagnostic confirmation after they noticed symptom compared with those who waited for $\leq 3$ months. This may in part reflect differences in knowledge about 
Table 2 Multivariable analysis showing factors associated with advanced stage at diagnosis of cervical cancer in patients residing in Addis Ababa, 2018

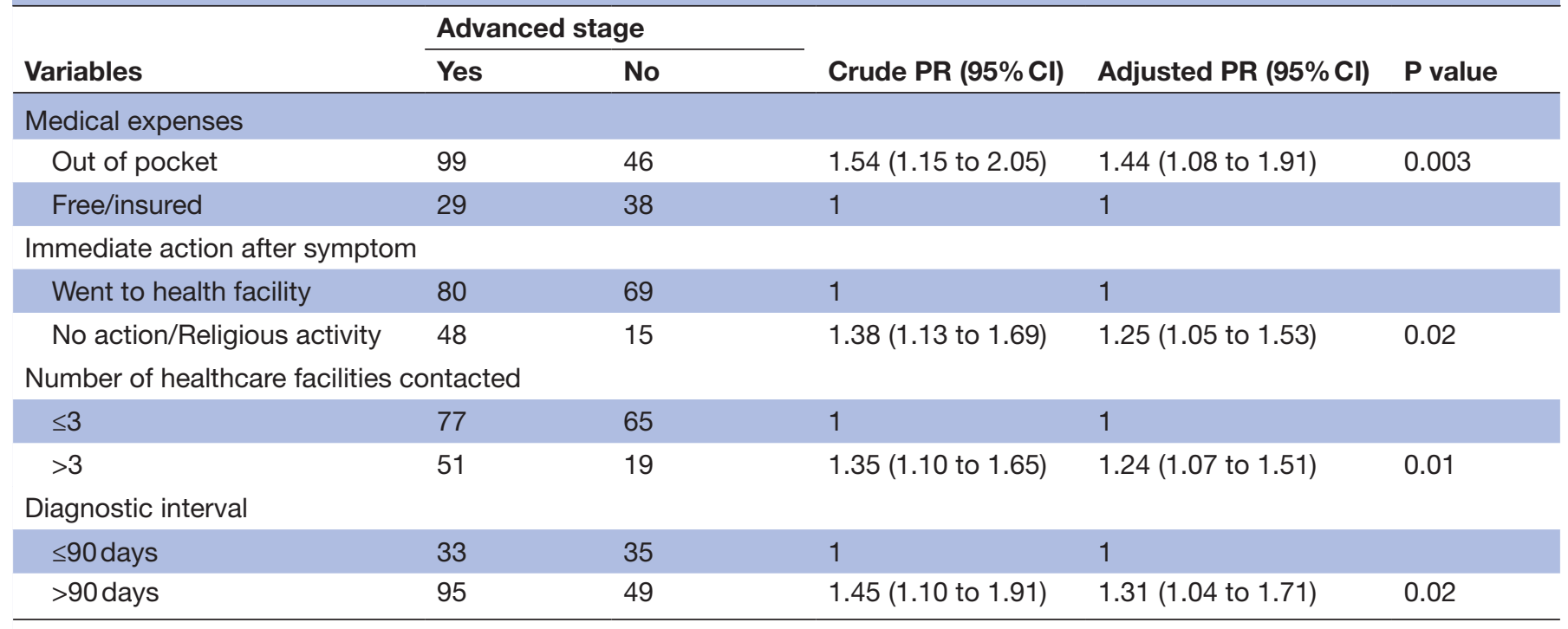

PR, prevalence ratio.

early detection of cervical cancer and treatments between the two groups of women, as well as differences in access to care. ${ }^{10}$ Thus, there is a need for concerted efforts to enhance community awareness about cervical cancer prevention and early detection in order to minimise delays in the diagnosis of the disease.

More than four out of five patients, who went to practise religious activities immediately after symptom recognition, were found to be diagnosed at advanced stage of cervical cancer. In Ethiopia, it is not uncommon for patients to seek prayer or use holy water (Tsebel) as a remedy for their illnesses before turning to conventional medicine. ${ }^{23}$ A qualitative study from Ethiopia reported that patients with cervical cancer have a strong belief that 'Tsebel (holy water)' will cure one from the disease. ${ }^{10}$ Similarly, seeking traditional and religious practices for cervical cancer care has been associated with advancedstage disease in other parts of Africa. ${ }^{8}$

Financial hardship is a barrier to accessing healthcare, leading to cancer progression and poor outcome. ${ }^{24}$ Consistent with our findings, previous studies conducted in Sudan ${ }^{20}$ and Uganda ${ }^{11}$ associated advanced stage with financial difficulties or being uninsured. Another study conducted among patients with gynaecological cancer also reported that women with financial hardship are seven times more likely to avoid or delay their cancer care. ${ }^{25}$ Providing free diagnostic and treatment services to all women with cervical cancer needs to be incorporated into the government's strategy on cervical cancer care. This will be in line with the WHO's global efforts to ensure universal health coverage. ${ }^{26}$

The strength of this study is the use of population-based cancer registry to document strong association between late-stage diagnosis and patient and health system factors, including diagnostic delay, in African settings. The registry, however, may not capture all incident cases diagnosed in the city because some patients might never have visited healthcare facilities or have visited local healthcare facilities that do not report cases to the cancer registry. Also, interpretation of our findings may be affected by recall bias about dates of symptom recognition and presentations, although we do not expect the biases to differ between patients diagnosed with early-stage and advanced-stage diseases.

\section{CONCLUSIONS}

Using a population-based study, we found that more than two-thirds of patients with cervical cancer in Addis Ababa are diagnosed at advanced stage of the disease, which was strongly associated with diagnostic delay, failure to take immediate action following symptom recognition and paying medical bill out of pocket. These findings underscore the need for public health campaigns and programmes to raise awareness about the severity of the disease and preventive measures to be taken and to expand the availability of screening services and policies to improve the affordability of cancer care in the city. Of note, implementing free diagnostic service would ensure accessibility to care for an increasing number of patients with precancerous lesion or early-stage disease through the ongoing scaled-up screening programme by the Ethiopian government.

Author affiliations

${ }^{1}$ Preventive Medicine, School of Public Health, Addis Ababa University, Addis Ababa, Ethiopia

${ }^{2}$ Public Health, College of Medicine and Health Sciences, Wachemo University, Hosanna, Ethiopia

${ }^{3}$ Public Health, College of Medicine and Health Sciences, Adigrat University, Adigrat, Ethiopia 
${ }^{4}$ Oncology, School of Medicine, Addis Ababa University, Addis Ababa, Ethiopia ${ }^{5}$ Department of Gynaecology, Institute of Medical Epidemiology, Biostatistics and Informatics, Martin-Luther-Universitat Halle-Wittenberg, Halle, Saxony-Anhalt, Germany

${ }^{6}$ Surveillance \& Health Services Research, American Cancer Society, Atlanta, Georgia, USA

Acknowledgements The authors would like to acknowledge the American Cancer Society for funding of the study and Addis Ababa University College of Health Sciences for the administrative support. The authors are also grateful to the study participants for their cooperation.

Contributors ND, AG, AdA, AW, MA and AJ were involved in the conception of the study, methodological design of the study, analysis and data interpretation. ND and AJ wrote the first draft of the manuscript. AA, WT and EJK were involved in the methodology of the study, data collection/extraction, visualisation of the data and data interpretation. All authors have revised the manuscript.

Funding This work was supported by the American Cancer Society. Award/Grant number is not applicable.

Competing interests None declared.

Patient consent for publication Not required.

Ethics approval This study was approved by the Institutional Review Board (IRB) of Addis Ababa University, College of Health Sciences (approval number: 005/19/ SPH). All participants of the study were informed about the study and they gave their written consent to be included in the study.

Provenance and peer review Not commissioned; externally peer reviewed.

Data availability statement Data are available upon reasonable request.

Supplemental material This content has been supplied by the author(s). It has not been vetted by BMJ Publishing Group Limited (BMJ) and may not have been peer-reviewed. Any opinions or recommendations discussed are solely those of the author(s) and are not endorsed by BMJ. BMJ disclaims all liability and responsibility arising from any reliance placed on the content. Where the content includes any translated material, BMJ does not warrant the accuracy and reliability of the translations (including but not limited to local regulations, clinical guidelines, terminology, drug names and drug dosages), and is not responsible for any error and/or omissions arising from translation and adaptation or otherwise.

Open access This is an open access article distributed in accordance with the Creative Commons Attribution Non Commercial (CC BY-NC 4.0) license, which permits others to distribute, remix, adapt, build upon this work non-commercially, and license their derivative works on different terms, provided the original work is properly cited, appropriate credit is given, any changes made indicated, and the use is non-commercial. See: http://creativecommons.org/licenses/by-nc/4.0/.

\section{ORCID iDs}

Nebiyu Dereje http://orcid.org/0000-0001-5406-4171

Alem Gebremariam http://orcid.org/0000-0003-2173-6685

Eva Johanna Kantelhardt http://orcid.org/0000-0001-7935-719X

\section{REFERENCES}

1 Bray F, Ferlay J, Soerjomataram I, et al. Global cancer statistics 2018: GLOBOCAN estimates of incidence and mortality worldwide for 36 cancers in 185 countries. CA Cancer J Clin 2018;68:394-424.

2 de Martel C, Plummer M, Vignat J, et al. Worldwide burden of cancer attributable to HPV by site, country and HPV type. Int $J$ Cancer 2017;141:664-70.

3 Mishra GA, Pimple SA, Shastri SS. An overview of prevention and early detection of cervical cancers. Indian J Med Paediatr Oncol 2011;32:125-32.

4 Begoinn M, Mathewos A, Aynalem A, et al. Cervical cancer in Ethiopia - predictors of advanced stage and prolonged time to diagnosis. Infect Agent Cancer 2019;14:36.
5 Kantelhardt EJ, Moelle U, Begoinn M, et al. Cervical cancer in Ethiopia: survival of 1,059 patients who received oncologic therapy. Oncologist 2014;19:727-34.

6 Jemal A, Bray F, Forman D, et al. Cancer burden in Africa and opportunities for prevention. Cancer 2012;118:4372-84.

7 Dunyo P, Effah K, Udofia EA. Factors associated with late presentation of cervical cancer cases at a district Hospital: a retrospective study. BMC Public Health 2018;18:1156.

8 Mlange R, Matovelo D, Rambau P, et al. Patient and disease characteristics associated with late tumour stage at presentation of cervical cancer in northwestern Tanzania. BMC Womens Health 2016;16:5

9 Kirema MF, Wagoro M, Carole A, et al. Socio-Demographic factors associated with advanced stage of cervical cancer at diagnosis in Kenyatta national Hospital, Kenya: a cross sectional study. J Cancer Sci Ther 2017;9:554-61.

10 Birhanu Z, Abdissa A, Belachew T, et al. Health seeking behavior for cervical cancer in Ethiopia: a qualitative study. Int $J$ Equity Health 2012;11:83.

11 Mwaka AD, Garimoi CO, Were EM, et al. Social, demographic and healthcare factors associated with stage at diagnosis of cervical cancer: cross-sectional study in a tertiary hospital in northern Uganda. BMJ Open 2016;6:e007690.

12 Timotewos G, Solomon A, Mathewos A, et al. First data from a population based cancer registry in Ethiopia. Cancer Epidemiol 2018;53:93-8.

13 FIGO Committee on Gynecologic Oncology. Figo staging for carcinoma of the vulva, cervix, and corpus uteri. Int J Gynaecol Obstet 2014:125:97-8.

14 Marth C, Landoni F, Mahner S, et al. Cervical cancer: ESMO clinical practice guidelines for diagnosis, treatment and follow-up. Ann Oncol 2017;28:iv72-83.

15 Fatima O, Rahou ZH, Bouchra HR, et al. The measurement of delay in diagnosis and treatment among Moroccan women with cervical cancer. Cancer and Oncology Research 2017;5:10-19.

16 Deepak G, Gita K, Rajan P, et al. Estimates of delays in diagnosis of cervical cancer in Nepal. BMC Women's Health 2014;14.

17 Gyenwali D, Pariyar J, Onta SR. Factors associated with late diagnosis of cervical cancer in Nepal. Asian Pac J Cancer Prev 2013;14:4373-7.

18 Barros AJD, Hirakata VN. Alternatives for logistic regression in cross-sectional studies: an empirical comparison of models that directly estimate the prevalence ratio. BMC Med Res Methodol 2003;3:21.

19 Dereje N, Addissie A, Worku A, et al. Extent and predictors of delays in diagnosis of cervical cancer in Addis Ababa, Ethiopia: a population-based prospective study. JCO Glob Oncol 2020;6:277-84.

20 Ibrahim A, Rasch V, Pukkala E, et al. Predictors of cervical cancer being at an advanced stage at diagnosis in Sudan. Int $J$ Womens Health 2011;3:385.

21 Ng'ang'a A, Nyangasi M, Nkonge NG, et al. Predictors of cervical cancer screening among Kenyan women: results of a nested casecontrol study in a nationally representative survey. BMC Public Health 2018;18:1221.

22 Bruni LAG, Serrano B, Mena M, et al. Human papillomavirus and related diseases in Ethiopia. ICO/IARC information centre on HPV and cancer (HPV information centre) 2018.

23 Kebede W, Kebede K. Psychosocial experiences and needs of women diagnosed with cervical cancer in Ethiopia. Int Soc Work 2017;60:1632-46.

24 Perrone F, Jommi C, Di Maio M, et al. The association of financial difficulties with clinical outcomes in cancer patients: secondary analysis of 16 academic prospective clinical trials conducted in Italy. Ann Oncol 2016;27:2224-9.

25 Bouberhan S, Shea M, Kennedy A, et al. Financial toxicity in gynecologic oncology. Gynecol Oncol 2019;154:8-12.

26 Knaul FM, Bhadelia A, Atun R, et al. Achieving effective universal health coverage and diagonal approaches to care for chronic illnesses. Health Aff 2015;34:1514-22. 